\title{
Outcomes of Various Treatment Modalities for Lumbar Spinal Ailments in Elite Athletes: A Literature Review
}

\author{
Akshay Gadia ${ }^{1}$, Kunal Shah ${ }^{2}$, Abhay Nene ${ }^{1}$ \\ ${ }^{1}$ Department of Spine, Wockhardt Hospital, Mumbai, India \\ "We Are Spine" Centre, Mumbai, India
}

Lumbar spinal injuries are common in elite athletes, who can present with a spectrum of ailments ranging from lumbar strain to prolapsed intervertebral discs. Sequelae can include neurological impairment and lumbar instability among other possible outcomes. This group of patients is unique in terms of their clinicoradiological presentation and treatment modalities. The primary goals of treatment are a rapid return to play and prevention of recurrence, thus prolonging the athlete's professional career. Treatment modalities can range from activity restriction to nerve root blocks and surgery. A successful treatment outcome is based on timely diagnosis, treatment suiting the demands of the particular sport, and early rehabilitation. A multidisciplinary team approach involving the coach, rehabilitation specialist, pain management specialist, and spine surgeon helps in planning appropriate treatment. In this article, we review special considerations in the elite athletic population with lumbar spinal ailments as well as the outcomes of various treatment modalities.

Keywords: Low back pain; Athletes; Return to sport; Treatment; Pain management

\section{Introduction}

Low back pain is one of the common disabling events in the daily life of the general population; it is estimated that approximately $80 \%$ of the population will suffer from at least one episode of back pain during the course of their life [1]. In a prospective study of college freshman football players, McCarrol et al. [2] found that 30\% (44 of 145) of patients had lost playing time due to low back pain. In another study, the authors found that $38 \%$ of tennis players had missed at least one tournament due to low back pain
[3]. Spinal injuries also have psychosocial and financial implications on an athlete [4]. The number of adolescents and adults involved in high-demand sports is increasing, which has led to heightened awareness about low back injuries in this special subset of the population.

The majority of lumbar spinal injuries does not pose a serious threat and can be managed nonoperatively. However, for a professional athlete, this scenario is entirely different. In contrast to the general population, who might participate in occasional recreational athletic activities, the livelihood of an elite athlete entirely depends on the sport

Received Nov 26, 2017; Revised Dec 6, 2017; Accepted Dec 17, 2017

Corresponding author: Kunal Shah

"We Are Spine" Centre, Aarav Polyclinic, 101 Excel Arcade, Opposite Telephone Exchange, LBS Road, Ghatkopar West, Mumbai 400086, India

Tel: +91-9930731911, Fax: +91-022-61784444, E-mail: orthokunal@yahoo.com 
in which they are involved. Lumbar spinal injuries in athletes can lead to a shortened career, poor performance, or the inability to perform at all. A small percentage of these injuries require surgical intervention. Following a lumbar spinal injury and treatment, an elite athlete is typically concerned about reaching their preinjury level of performance as quickly as possible.

Traditional measures, such as the Visual Analog Scale (VAS), modified Oswestry Disability Index (ODI), and 36-item Short-Form Health Survey (SF-36), evaluate the ability of the patient to perform activities of daily living without pain following a particular intervention in the lumbar spine. The outcomes of various treatment modalities for lumbar spinal injuries and for return to sport (RTS) are scarcely described in the literature. This manuscript provides a brief review of the outcomes reported in the literature following operative and nonoperative treatment modalities for various etiologies of lumbar spinal injury in elite athletes.

\section{Prevalence}

Approximately $30 \%$ of athletes will have at least one episode of acute low back pain during their career [5]. Recently, in a cross-sectional study of 1,114 elite athletes, Fett et al. [6] reported that the lifetime prevalence of back pain in an elite athlete was $88.5 \%$; the 12 -month prevalence was $81.1 \%$; the 3 -month prevalence was $68.3 \%$; and the point prevalence was $49.0 \%$, compared with $80.7 \%$, $69.9 \%, 59.0 \%$, and $42.8 \%$, respectively, in a control group. Increased trunk length and stiff lower extremities are known predisposing factors for acute low back pain in athletes [7]. In a study of 4,790 college students involved in over 17 various sports over a 10 -year period, lumbar spinal injury rates were significantly higher in American football players and gymnasts [8]. Footballers, particularly offensive and defensive linemen, are more prone to lumbar disc herniations [9].

\section{Biomechanical considerations}

Athletes involved in sports requiring repetitive axial loading, hyperextension, direct impact, and twisting are highly prone to lumbar spinal injuries [10]. It is therefore important for the treating physician to understand the basic anatomy of the lumbar spinal and to be aware of the injury patterns that can occur. Repetitive axial loading of the low back can lead to lumbar disc herniation, which can even lead to a surgical emergency in cases of compression of the cauda equina [11]. Athletes involved in sports leading to repetitive hyperextension and causing excessive stress on posterior elements of vertebral body are at high risk for spondylolysis, with or without spondylolisthesis [12].

\section{Lumbar Spinal Injuries: Lumbar Strains}

Lumbar strain is one of the most common spinal ailments, responsible for $70 \%$ of back pain in the general population [13]. As with the general population, lumbar strains are also one of the most common injuries encountered in professional athletes. The majority of lumbar strains in athletes can be managed nonoperatively. A brief rest period of 1 to 2 days is typically followed by physical rehabilitation. In case of severe muscle spasms, nonsteroidal anti-inflammatory drugs (NSAIDs), with or without muscle relaxants, are prescribed. Once the patient is relatively pain free, physical rehabilitation begins, which includes stretching and strengthening of the relevant muscles. Athletes return to their sport gradually once the pain is under control [14,15], and pain levels are considered to be a guide for progressing with activity levels.

Spinal manipulation therapy (SMT) is widely described in the literature as a treatment modality for lumbar strains in the general population. However, there is scarce literature pertaining to lumbar strains in professional athletes. In a systemic review, Dagenais et al. [16] found SMT was effective in the short-term as well as in the long-term management of acute low back pain. In a systemic review of 43 randomized controlled trials (RCTs), Bronfort et al. [17] found moderate evidence for SMT being more effective in the short-term management of acute low back pain compared with mobilization. Chronic low back pain showed moderate improvement with SMT, which was as effective as NSAIDs and more effective than physical therapy for providing long-term relief. In a Cochrane review of 26 RCTs, Rubinstein et al. [18] concluded that there was no difference between SMT and other interventions for reducing pain and improving functional outcome in patients with chronic low back pain.

Additional high-quality studies are needed to evaluate the role of SMT in management of low back pain due to lumbar strains in athletes. 


\section{Lumbar Disc Herniations}

Nonoperative treatment and appropriate physical rehabilitation are the most important components of the management of lumbar disc herniations in athletes, and a multidisciplinary team approach is required for a successful outcome. Surgery is necessary in patients presenting with worsening neurological deficit, involvement of sphincters, and failure to respond to conservative treatment. The decision on surgery should be based upon a consensus of the nonoperative care specialist, the physical rehabilitation specialist, and the operative care specialist [19]. A patient with lumbar disc herniations can be treated surgically either with microdiscectomy or lumbar fusion, treatment modalities that have been associated with excellent functional outcomes in the general population [20]. For athletes undergoing spinal surgery for various etiologies, RTS is the most important concern [21], thus postoperative care in this subset of the population can be challenging. Athletes are often ideal patients, given they are aware of the amount of physical therapy required following spinal surgery; they are highly motivated to recover rapidly and to RTS as early as possible [22]. Successful RTS following spinal surgery is determined by many factors: a correct diagnosis, appropriately planned and effective surgery, and appropriately planned physical rehabilitation [19].

\section{Outcomes of nonoperative treatment}

In general, lumbar disc herniation in athletes has a favorable outcome. More than $90 \%$ of players respond well to nonoperative treatment, and most patients RTS within 6 weeks of sciatica onset [23]. In a review, Iwamoto et al. [24] analyzed seven studies ( $\mathrm{n}=71$ athletes) regarding symptomatic lumbar disc herniations after conservative treatment. Treatment consisted of rest, oral medications, and physical therapy. The RTS rate was $79 \%$, after an average period of 4.7 months. These athletes were able to maintain their participation in sports for at least 6 months. The severity of symptoms was found to have a negative correlation with the timing of their return to sporting activities. The authors also noted that radicular pain responded better to conservative treatment compared with axial back pain and neurological weakness. In another retrospective study of 342 professional athletes, Hsu et al. [25] studied the outcome of nonoperative and surgical treatment of lumbar disc herniations. Athletes involved in this study belonged to four major American sports groups (hockey, football, basketball, and baseball). Of 226 athletes undergoing surgical treatment for lumbar disc herniation, $82 \%$ successfully returned to sports, with an average 3.3-year sporting career following surgery. Of 116 patients treated by nonoperative means (activity modification, physical therapy, and epidural steroid injections), $84 \%$ returned to sport, with an average career length of 3.5 years [25]. RTS rates also varied depending upon the sport in which the athlete was involved. Overall, baseball players had the highest rate of RTS whereas football players had the lowest rate. Football players gained maximum benefits from surgery compared with players involved in other sports, and football players undergoing surgical treatment had longer career lengths compared with the nonsurgical group. Baseball players undergoing surgery had a shorter career compared with the nonoperative group [25].

Earhart et al. [26] analyzed 64 professional baseball players with 69 herniated lumbar discs. Some 40 players were treated surgically, whereas 29 were treated by nonoperative modalities (physical therapy, epidural steroid injection, and activity modification). Overall, $97 \%$ of athletes returned to sport at an average period of 6.6 months. Players treated nonoperatively had an early RTS (average 3.6 months) compared with players treated surgically (average 8.7 months).

Vangelder et al. [27] devised a phased rehabilitation protocol in athletes undergoing nonoperative treatment for lumbar disc herniation based upon the rehabilitation framework around the healing phases of the disc.

Phase 1: nonrotational/nonflexion phase (acute inflammatory phase) lasts from 0 to 6 days; phase 2: counter-rotation/flexion phase (repair phase) lasts from 3 to 20 days; phase 3: rotational phase/power development (remodeling phase) lasts from 9 days to full rotation; and phase 4: full RTS. The authors concluded that it is vital that the physical therapy prescription be individualized depending upon the assessment of the athlete, addressing movements in all necessary planes of motion, and under all extrinsic and intrinsic demands of the athlete.

\section{Selective nerve root blocks and epidural steroid in- jection}

Indications for selective nerve root blocks and epidural steroid injections include lumbar disc herniation or annular tear with or without radiculopathy. A selective 
nerve root block involves injecting a local anesthetic around the involved nerve under fluoroscopic guidance. Corticosteroids are frequently added to achieve longterm relief, based on their anti-inflammatory properties. Various techniques have been described including the transforaminal, interlaminar, and caudal epidural techniques. Transforaminal epidural steroid injections allow more ventral placement of the drug and are thus a more precise treatment compared with interlaminar and caudal epidural steroid injections. In a case control study on transforaminal versus interlaminar steroid injections for the treatment of symptomatic disc herniations, Schaufele et al. [28] reported that the transforaminal group had significant short-term improvement and fewer surgical interventions in the long term compared with the interlaminar group.

In a retrospective analysis of a prospective study, Jackson et al. [29] studied 32 competitive athletes treated with epidural steroid injections for symptomatic lumbar disc herniation with radiculopathy. Each athlete was also managed by other modalities of nonoperative treatment for an average period of 3.6 months (minimum 2 weeks) from the onset of symptoms. The authors reported that $44 \%$ of patients achieved significant pain relief and rapidly returned to their sport.

In another retrospective analysis, Krych et al. [30] studied 17 National Football League athletes with 27 distinct lumbar disc herniations, who received a total of 37 lumbar epidural steroid injections. The procedure was performed either using a transforaminal or the interlaminar approach, at an average period of 4 days from the onset of symptoms. The players were able to RTS 24 times (89\%) out of 27 distinct episodes of lumbar disc herniations. Four patients required repeat injections for the same episode, of which three eventually required surgery. The authors also analyzed the risk factors for failed intervention. They found that athletes with a poor response correlated with having an magnetic resonance imaging (MRI) finding of disc sequestration and neurological deficit. They concluded that epidural steroid injections are a safe and effective treatment for lumbar disc herniations in athletes and that the injections provided either an alternative to surgery or offered relief until the surgery could be performed off-season. There was no difference in outcomes between the transforaminal and the interlaminar approach in this study.

\section{Surgery}

The Spine Patient Outcomes Research Trial found excellent clinical outcomes in patients with lumbar disc herniation, irrespective of the treatment modality (conservative or surgical) [20]. There was a significant crossover of patients between the two groups in this randomized trial. Though the intent to treat analysis had shown a trend toward greater improvements in a group undergoing surgery, these differences were statistically insignificant [31]. These randomized trials described the outcomes of lumbar disc herniation treatment in the general population; however, these results do not necessarily hold true in the case of professional athletes involved in competitive contact sports. Parameters such as career longevity, performance, and RTS can aptly be described as representative outcome measures when evaluating any intervention in this subset of the population. The Professional Athlete Spine Initiative [25] was a retrospective cohort study of 342 professional athletes from four major North American sports from 1972 to 2008 who were diagnosed with lumbar disc herniations. Some 226 underwent surgical treatment (lumbar discectomy), whereas 116 underwent conservative treatment. Functional outcomes were evaluated by return to play (RTP) rates, number of games played after intervention, and length of career in years. Approximately 81\% (184 of 226) of the operated patients returned to play at an average of 3.3 years following surgery. Survivorship analysis has shown that approximately $62.3 \%$ of players were expected to remain active for approximately 2 years following treatment. There was a significant difference in RTP rates between the individual sport cohorts: baseball players had the highest RTP rates, whereas football players had the lowest. The player's professional experience before the injury was a positive predictive factor for length of career, and increased athlete age was a negative predictor. An analysis of independent cohorts suggested that NFL players undergoing lumbar microdiscectomy demonstrated significantly longer career lengths than the players treated nonoperatively when compared with other sports cohorts. The authors also calculated the performance score for each individual player depending on their playing position; there was no statistical difference between the treatment groups. Nor were differences found in the performance scores before and after treatment. The authors concluded that players at all positions can return to a preinjury level of performance 
following either nonoperative or surgical treatment for lumbar disc herniations.

In another descriptive study, Schroeder et al. [32], evaluated 87 ice hockey players to determine performancebased outcomes following nonoperative and surgical treatment for lumbar disc herniations. Some $85 \%$ of the patients had returned to sport, with a significant decrease in all players' performance after a lumbar disc herniation in games played per season, points scored per game, and performance score. Analysis of posttreatment results showed that there was no significant difference in performance scores between the nonoperative and surgical groups.

The approach to disc pathology differs in children compared with adults. Pediatric patients do not respond well to nonoperative treatment and usually require surgical treatment. Patients and parents are frequently concerned about RTP following lumbar discectomy [21]. Although there is scarce literature, Burnett and Sonntag [22], Eck and Riley [33], and Cahill et al. [34] have suggested that there is no contraindication for pediatric patients to RTS following lumbar discectomy. Cahill et al. [34] reviewed 87 pediatric patients who had undergone lumbar microdiscectomy; $64 \%$ of the patients were athletes who were allowed to RTS at 8 to 12 weeks postoperatively.

Although lumbar microdiscectomy does not risk spinal instability, the possibility of recurrent disc herniations and further disc degeneration should be discussed with the patients and their parents before allowing a complete RTS. An athlete is expected to undergo structured rehabilitation following nonoperative or surgical treatment before returning to sport. Physical therapy should aim at building strong core muscles with lumbar stretching and sportspecific activities. Haus and Micheli [15] recommended that athletes usually return to activity at 3 to 6 months after nonoperative treatment and at 6 to 12 months after surgery.

In a retrospective review of 59 professional and Olympic athletes undergoing lumbar microdiscectomy, Watkins et al. [35] found that $88 \%$ of patients returned to active sport at an average period of 5.2 months following surgery. However, there was no performance-based outcome assessed in this study. The authors highlighted the role of trunk stabilization and strengthening exercises for athletes to be able to return to their respective sports.

\section{Degenerative Disc Disease}

Degenerative disc disease (DDD) is a term used for progressive degeneration of the intervertebral disc that is characterized by disc dehydration, annular tear, and loss of disc height, ultimately leading to a fusion of motion segment. Historically, abnormal physical loading across the motion segment was thought to be the predisposing factor for lumbar DDD [36]; however, much high-level evidence exists in the literature to support the theory that genetic predisposition, aging, smoking, and occupational hazard are associated with the development of DDD [37]. Wrestling, swimming, rowing, hockey, ballet, diving, weight lifting, baseball, and golf are associated with a higher incidence of lumbar disc degeneration [38].

\section{Nonoperative treatment}

Nonsurgical management is the mainstay of treatment for lumbar DDD in professional athletes. Physical therapy along with NSAIDs are routinely prescribed. There are multiple physical therapy protocols for the management of lumbar DDD; however, the combination of lumbar mobilization, core strengthening, and biopsychosocial support provide the optimum outcome [39].

Cooke and Lutz [14] described a 5-stage rehabilitation protocol for nonoperative management of an acute episode of DDD in professional athletes. Stage 1 (early protected stabilization) consists of bed rest limited to less than 2 days, followed by pharmacological and nonsurgical modalities (NSAIDs, superficial heat and cold, epidural steroid injections). Once the pain is under control, early lumbar range of movement exercises are started. Stage 2 (dynamic spinal stabilization) involves isometric strengthening of the lumbar extensor and abdominal muscles so as to reinforce the injured motion segment. Stage 3 (lumbar strengthening) comprises further lumbar strengthening to maintain the initial gains resulting from neuromuscular firing. Stage 4 (RTS activity) involves plyometric exercises composed of eccentric contraction, explosive concentric contraction, and resisted stretching. The authors also established criteria for RTS, involving (1) full, painless range of motion; (2) restoration of endurance and muscular strength; and (3) the ability to maintain the neutral posture of the spine during specific sport-related exercises. Stage 5 (maintenance program) consists of regular warmup exercises. The time duration of each stage varies ac- 
cording to each athlete's individual recovery.

\section{Facet joint injections, medial branch block, and ra- diofrequency neurotomy}

Pain arising from facet joints will present with axial, nonradiating, paraspinal back pain, worsening on extension. The prevalence of facet joint pain is between 15\% and 52\% of the general population with chronic low back pain [40]. Young athletes are typically prone to facet joint synovitis, whereas degenerative arthritis of the facet joints is noted in elderly athletes. Athletes involved in repetitive extension and torsion of the lumbar spine, specifically golfers and throwers, frequently encounter facet-related pain [41]. Medial branch block with intra-articular injections with local anesthetic and steroids can serve as a diagnostic modality and have therapeutic potential. Radiofrequency neurotomy involves ablating the medial branch using electric current to reduce the pain originating from the facet joint [42].

In a prospective audit of 15 patients with chronic low back pain, Dreyfuss et al. [43] recommended that careful patient selection through positive response to medial branch block was the only solid predictor of positive outcomes to facet joint denervation. The authors also suggested that parallel placement of needles under direct fluoroscopy had a denervation rate of over $90 \%$.

In a prospective study of 12 baseball pitchers with bilateral L4-L5 facet synovitis, Vad et al. [42] evaluated the role of radiofrequency ablation of the medial branch in suppressing the pain arising from facet joints. All 12 athletes having evidence of bilateral L4-L5 facet synovitis on MRI underwent fluoroscopic-guided intra-articular steroid injections. However, all the patients reported persistent pain at 8 weeks, and they underwent a diagnostic medial branch block, following which all the patients had positive results after undergoing radiofrequency neurotomy of the bilateral L4-L5 and L5-S1 facet joints. The authors reported significant improvements in pain (assessed by patient-reported VAS scores), and $83 \%$ of the patients were able to RTS at their preinjury level. These results were sustained for a minimum follow-up period of 1 year. The authors concluded that radiofrequency neurotomy of the facet joints provided safe, effective, and long-term relief of pain arising from facet synovitis in this specific group of athletes.

\section{Surgery}

Patients with DDD can be treated surgically either by lumbar fusion or lumbar total disc replacement (TDR), and outcomes in the general population are variable. To date there is a paucity of literature on lumbar fusion for DDD in professional athletes. In a series of athletes who returned to play after lumbar fusion, Schroeder et al. [32] reported on 8 hockey players who underwent single-level lumbar spinal fusion. There was no significant difference in the number of games played per season or the performance score either before or after the treatment.

Recently, Shifflett et al. [44] reviewed 34 golfers undergoing a fusion procedure for degenerative pathologies of the lumbar spine. Some $65 \%$ of the patients returned to practice and $52 \%$ of the patients returned to course play within 1 year of surgery. Some $77 \%$ of the patients were able to play the same amount of golf or more than before the fusion surgery. Of those patients who had not returned to their sport at 1 year, less than one-third of the patients stated that their back pain or leg pain was the limiting factor for returning to their sport.

Siepe et al. [45] reviewed 39 high-demand professional athletes who underwent TDR for lumbar DDD. The average follow-up period was 26.3 months, and the RTS rate was $94.9 \%$ ( 35 of 37 patients). Some $85 \%$ of the patients were completely satisfied with their procedure, and the average time for peak fitness was 5.2 months based on patient-reported surveys. Following TDR, 69\% of the patients returned to play within 3 months. It is noteworthy that in the entire cohort only two patients were involved in contact sports, and neither player was able to RTP after TDR.

Military personnel are a special group of individuals whose lumbar spines bear a great deal of force. They are involved in strenuous activities such as running long distances with heavy loads, diving, valley crossing, parachute jumping, and rope climbing. In an cohort-matched comparative analysis between TDR and lumbar fusion, Tumialan et al. [46] reported 10 (83\%) of 12 patients undergoing TDR returned to unrestricted full duty in an average period of 22.6 weeks. In a fusion cohort, eight (67\%) of 12 patients had returned to unrestricted activity in an average period of 32.4 weeks. Although this study suggested that TDR outcomes are favorable compared with the fusion study, the authors found some potential confounding factors. Although all symptoms resolved, the return to 
work in the fusion group depended on radiographic evidence of fusion; however, there are no such radiographic indicators for TDR that dictate the safe return to work. Moreover, surgeons tend to permit an early return to patients involved in a sedentary work environment.

\section{Spondylolysis and Spondylolisthesis}

Approximately $47 \%$ of low back pain in athletes is attributed to spondylolysis and spondylolisthesis [47]. Spondylolysis is a defect in the pars interarticularis; it is a stress fracture that occurs due to microtrauma due to repetitive hyperextension, flexion, and rotation of the lumbar spine [10]. Lumbar pain in an athlete is a stress fracture until proven otherwise [48]. Up to one-third of adolescent athlete patients presenting with complaints of low back pain have positive bone scans for stress fractures [49]. Competitive athletes, such as gymnasts, weight lifters, and football players are at increased risk of spondylolysis [10]. In a descriptive study of 3,132 competitive athletes, Rossi and Dragoni [50] found spondylolysis in 390 patients. They noted that the incidence was higher in certain sports, such as diving (40.3\%), wrestling (29.82\%), and weight lifting (22.68\%). In another descriptive study, 3,152 highlevel Spanish athletes were evaluated to determine the prevalence of spondylolysis in various sports. The authors reported spondylolysis in $27 \%$ of the throwing athletes, in $17 \%$ of the gymnasts, and in $17 \%$ of the rowers. An analysis of the biomechanical movements involved in the sports with a greater prevalence of spondylolysis was also performed. The authors suggested torsion against resistance as another possible causative factor for spondylolysis that should be added to the already known causative mechanisms: lumbar hyperextension and rotation [51].

\section{Nonoperative treatment}

The majority of patients with acute symptomatic spondylolysis can be managed successfully with nonoperative treatment. The primary aim of treatment of spondylolysis in athletes is to minimize pain while restoring function and motion. Acute symptomatic pars defects are managed initially with activity modifications, bracing, rest, and physical therapy. Lumbar extensions should be avoided so as to prevent shearing forces and thus prevent spondylolisthesis. In a review of the literature on spondylolysis among fast bowlers, Kothari et al. [52] suggested that early diagnosis and a short rest period is the key factor for an early RTS. The authors also proposed enforcing strict strategies for prevention of these injuries in adolescent fast bowlers. Klein et al. [53] reported a healing rate approaching $90 \%$ in patients with acute spondylolysis. Patients with chronic spondylolysis, however, are less likely to respond to conservative treatment. In a case control study of 132 athletes with spondylolysis, El Rassi et al. [54] demonstrated that athletes who refrained from sports for 3 months had an outcome 16.39 times better than those who continued with sports. Miller et al. [55] suggested that the majority of athletes managed nonoperatively for acute spondylolysis had good functional outcomes for up to 11 years.

\section{Pars interarticularis injections}

Although there is a great deal of peer-reviewed literature reported on the outcome of pars injections for spondylolysis in the general population, there is a paucity of such studies specifically aimed at athletes with chronic pars defects. These injections are performed under fluoroscopy with anesthetics alone (diagnostic) or with anesthetics and corticosteroids (therapeutic). The injections are made directly into the pseudarthrosis in the pars, given the direct site of pain generation is the pars fracture. Kershen et al. [56] retrospectively reviewed 121 patients undergoing pars injection with the aim of determining the accuracy and short-term efficacy of fluoroscopy-guided steroid/anesthetic injections for symptomatic pars defects. Patientreported VAS scores were used to measure outcomes. The authors concluded that $92 \%$ of fluoroscopy-guided injections were technically successful in patients with symptomatic spondylolysis, resulting in statistically significant pain reduction immediately post-injection and at 1 week post-injection.

Despite the lack of literature on pars injections for the treatment of symptomatic spondylolysis, it appears to be an attractive alternative for short-term management of chronic pars-related pain in athletes. Injecting anesthetic alone in cases of pars defect can identify pars as the pain generator, whereas the use of a corticosteroid along with a local anesthetic could be diagnostic as well as therapeutic.

\section{Surgery}

Surgical treatment is recommended for athletes who fail 
to improve after 6 months of nonoperative treatment. Surgery is also the preferred modality of treatment for adolescent athletes with high-grade spondylolisthesis because they are at significant risk of a further increase in vertebral slip [57]. Patients with spondylolisthesis can be treated with either direct pars repair or decompression with or without fusion.

Young patients with minimal spondylolisthesis, no radicular symptoms, and mild degenerative changes are ideal candidates for direct pars repair [58]. To date, many pars repair techniques have been described, including the Scott wiring technique, Morscher hook screw technique, and Buck's screw technique [59]. Of these approaches, Buck's screw is biomechanically the strongest and stiffest, whereas Scott's wiring is the least stable repair [60]. In a retrospective study of 16 patients with spondylolysis undergoing direct pars repair with the Buck's screw technique, Snyder et al. [61] demonstrated that Buck's screw repair provided a satisfactory clinical and radiological outcome, including an early RTS. In a review of minimally invasive versus conventional direct repair of pars for spondylolysis in athletes, Kolcun et al. [62] reported that patients undergoing minimally invasive pars repair had significantly higher rates of pain resolution and shorter recovery times. Both groups were comparable in terms of complication rates and RTP rates. Reitman and Esses [63] reported on four athletes who returned to sports within 6 months of Buck's repair for spondylolysis. All the athletes in this study had returned to their preinjury level of performance by 1 year. Gillis et al. [58] studied eight young athletes undergoing pars repair using minimally invasive techniques. Some $75 \%$ (6 of 8) of the athletes returned to their preinjury level of performance. Two patients who were unable to achieve the previous level of performance had spondylolysis that failed to fuse. Overall, there was improvement in patient-reported outcomes as measured by the VAS, ODI, and SF-36 scores. In a prospective study of 22 athletes, Debnath et al. [13] studied the clinical outcome and RTS rate after surgical treatment of spondylolysis. ODI and SF-36 scores were used to measure the outcome. Three patients received Scott's fusion and 19 patients received Buck's fusion. At the end of 2 years, there were statistically significant improvements in both the ODI as well as the SF-36 scores. Some 82\% (18/22) of the patients returned to their sporting activity in an average period of 7 months (range, 4-10 months). Hardcastle [64] reported good results of local screw fusion of pars interarticularis defects in 10 cricket bowlers. Unrestricted athletic activity was permitted once union was evident on oblique computed tomography scans. Some 70\% (7/10) of the patients had returned to sport at 3-6 months. In a study of 20 athletes involved in baseball, tennis, and golf, Nozawa et al. [65] analyzed the results of pars interarticularis defect repair by segmental wire fixation. Outcomes were evaluated by radiographic examination, Japanese Orthopaedic Association (JOA) score, preoperative and postoperative activity levels, and the rates of intensity and complications. The authors reported bony fusion at the repair site in all the patients, with a significant improvement in JOA scores (recovery rate $80.4 \%$ ). All the patients returned to sporting activity, although to varying degrees. The authors reported no major complications.

Spondylolysis with spondylolisthesis and degenerative changes that are refractory to nonoperative treatment are amenable to posterolateral fusion, with success rates close to $90 \%$. Helenius et al. [66] studied 108 young patients undergoing in situ posterolateral fusion for lowgrade spondylolisthesis, with a mean follow-up period of 20.8 years. The authors reported satisfactory functional outcomes as measured by the Scoliosis Research Society questionnaire and the ODI. Lamberg et al. [67] reviewed 69 young patients with high-grade spondylolisthesis undergoing either posterolateral, anterior, or circumferential in situ fusion. At an average follow-up of 17.2 years, all the treatment groups had good ODI scores. The circumferential fusion group had slightly better outcomes compared with the other treatment groups.

\section{Lumbar Canal Stenosis in Athletes}

Unlike the degenerative process in the middle-aged and elderly age groups, lumbar canal stenosis in athletes is a result of structural pathologies such as spondylolisthesis, scoliosis, and lumbar disc herniations. The initial treatment is focused on nonoperative treatment such as refraining from sports and taking NSAIDs, followed by progressive therapy. Patients with a poor response to nonoperative treatment, significant neurological deficits, cauda equina syndrome, and spinal instability will require surgical treatment [33]. There is a paucity of literature on outcome evaluations of isolated decompression in athletes. Current recommendations for RTS are based on expert opinions. Abla et al. [68], in a survey of members of the North American Spine Society, reported that the 
majority of surgeons will allow their patient to resume golf at 4 to 8 weeks after surgery. Eck and Riley [33] recommended a return to noncontact sports at 4 to 6 months and completely refraining from contact sports.

\section{Conclusions}

Degenerative conditions of the lumbar spine are common in high-level professional athletes. The management of these injuries is different than that for the general population due to the diversity in treatment outcomes. Most lumbar spinal injuries in elite athletes can be managed nonoperatively, with surgical treatment as an option for patients who do not respond to nonoperative treatment.

There is no consensus in the literature regarding standardized criteria for RTP following lumbar surgery. Lumbar disc herniation in athletes has an excellent clinical outcome following nonoperative as well as operative treatment, irrespective of the nature of the sport in which the athlete is involved. However, surgical treatment outcomes are poor in athletes whose lower back is subject to repetitive torsional force. DDD is more common in professional athletes and its etiology is multifactorial. Acute spondylolysis in an elite athlete can usually be successfully managed nonoperatively. Whenever surgical treatment is required, however, direct pars repair provides a motion-sparing approach to treatment and is the preferred modality. It has been shown to be associated with good outcomes and a successful RTS.

\section{Conflict of Interest}

No potential conflict of interest relevant to this article was reported.

\section{References}

1. Tones M, Moss N, Polly DW Jr. A review of quality of life and psychosocial issues in scoliosis. Spine (Phila Pa 1976) 2006;31:3027-38.

2. McCarroll JR, Miller JM, Ritter MA. Lumbar spondylolysis and spondylolisthesis in college football players: a prospective study. Am J Sports Med 1986;14:404-6.

3. Hainline B. Low back injury. Clin Sports Med 1995;14:241-65.

4. Khazaeipour Z, Norouzi-Javidan A, Kaveh M, Khan- zadeh Mehrabani F, Kazazi E, Emami-Razavi SH. Psychosocial outcomes following spinal cord injury in Iran. J Spinal Cord Med 2014;37:338-45.

5. Dreisinger TE, Nelson B. Management of back pain in athletes. Sports Med 1996;21:313-20.

6. Fett D, Trompeter K, Platen P. Back pain in elite sports: a cross-sectional study on 1114 athletes. PLoS One 2017;12:e180130.

7. Fairbank JC, Pynsent PB, van Poortvliet JA, Phillips $\mathrm{H}$. Influence of anthropometric factors and joint laxity in the incidence of adolescent back pain. Spine (Phila Pa 1976) 1984;9:461-4.

8. Keene JS, Albert MJ, Springer SL, Drummond DS, Clancy WG Jr. Back injuries in college athletes. J Spinal Disord 1989;2:190-5.

9. Hsu WK. Performance-based outcomes following lumbar discectomy in professional athletes in the National Football League. Spine (Phila Pa 1976) 2010;35:1247-51.

10. Bono CM. Low-back pain in athletes. J Bone Joint Surg Am 2004;86-A:382-96.

11. Purcell L, Micheli L. Low back pain in young athletes. Sports Health 2009;1:212-22.

12. Hutton WC, Stott JR, Cyron BM. Is spondylolysis a fatigue fracture? Spine 1977;2:202-9.

13. Debnath UK, Freeman BJ, Gregory P, de la Harpe D, Kerslake RW, Webb JK. Clinical outcome and return to sport after the surgical treatment of spondylolysis in young athletes. J Bone Joint Surg Br 2003;85:2449.

14. Cooke PM, Lutz GE. Internal disc disruption and axial back pain in the athlete. Phys Med Rehabil Clin N Am 2000;11:837-65.

15. Haus BM, Micheli LJ. Back pain in the pediatric and adolescent athlete. Clin Sports Med 2012;31:423-40.

16. Dagenais S, Gay RE, Tricco AC, Freeman MD, Mayer JM. NASS contemporary concepts in spine care: spinal manipulation therapy for acute low back pain. Spine J 2010;10:918-40.

17. Bronfort G, Haas M, Evans RL, Bouter LM. Efficacy of spinal manipulation and mobilization for low back pain and neck pain: a systematic review and best evidence synthesis. Spine J 2004;4:335-56.

18. Rubinstein SM, van Middelkoop M, Assendelft WJ, de Boer MR, van Tulder MW. Spinal manipulative therapy for chronic low-back pain: an update of a Cochrane review. Spine (Phila Pa 1976) 2011;36:E825- 
46.

19. Watkins $R$, Watkins R. Return to play after spinal surgery. In: Micheli L, Stein C, O’Brien M, d'Hemecourt $\mathrm{P}$, editors. Spinal injuries and conditions in young athletes. New York (NY): Springer; 2014.

20. Weinstein JN, Lurie JD, Tosteson TD, et al. Surgical vs nonoperative treatment for lumbar disk herniation: the Spine Patient Outcomes Research Trial (SPORT) observational cohort. JAMA 2006;296:2451-9.

21. Rubery PT, Bradford DS. Athletic activity after spine surgery in children and adolescents: results of a survey. Spine (Phila Pa 1976) 2002;27:423-7.

22. Burnett MG, Sonntag VK. Return to contact sports after spinal surgery. Neurosurg Focus 2006;21:E5.

23. Lively MW, Bailes JE Jr. Acute lumbar disk injuries in active patients: making optimal management decisions. Phys Sportsmed 2005;33:21-7.

24. Iwamoto J, Sato Y, Takeda T, Matsumoto H. The return to sports activity after conservative or surgical treatment in athletes with lumbar disc herniation. Am J Phys Med Rehabil 2010;89:1030-5.

25. Hsu WK, McCarthy KJ, Savage JW, et al. The Professional Athlete Spine Initiative: outcomes after lumbar disc herniation in 342 elite professional athletes. Spine J 2011;11:180-6.

26. Earhart JS, Roberts D, Roc G, Gryzlo S, Hsu W. Effects of lumbar disk herniation on the careers of professional baseball players. Orthopedics 2012;35:43-9.

27. Vangelder LH, Hoogenboom BJ, Vaughn DW. A phased rehabilitation protocol for athletes with lumbar intervertebral disc herniation. Int J Sports Phys Ther 2013;8:482-516.

28. Schaufele MK, Hatch L, Jones W. Interlaminar versus transforaminal epidural injections for the treatment of symptomatic lumbar intervertebral disc herniations. Pain Physician 2006;9:361-6.

29. Jackson DW, Rettig A, Wiltse LL. Epidural cortisone injections in the young athletic adult. Am J Sports Med 1980;8:239-43.

30. Krych AJ, Richman D, Drakos M, et al. Epidural steroid injection for lumbar disc herniation in NFL athletes. Med Sci Sports Exerc 2012;44:193-8.

31. Weinstein JN, Tosteson TD, Lurie JD, et al. Surgical vs nonoperative treatment for lumbar disk herniation: the Spine Patient Outcomes Research Trial (SPORT): a randomized trial. JAMA 2006;296:244150.
32. Schroeder GD, McCarthy KJ, Micev AJ, Terry MA, Hsu WK. Performance-based outcomes after nonoperative treatment, discectomy, and/or fusion for a lumbar disc herniation in National Hockey League athletes. Am J Sports Med 2013;41:2604-8.

33. Eck JC, Riley LH 3rd. Return to play after lumbar spine conditions and surgeries. Clin Sports Med 2004;23:367-79.

34. Cahill KS, Dunn I, Gunnarsson T, Proctor MR. Lumbar microdiscectomy in pediatric patients: a large single-institution series. J Neurosurg Spine 2010;12:165-70.

35. Watkins RG 4th, Williams LA, Watkins RG 3rd. Microscopic lumbar discectomy results for 60 cases in professional and Olympic athletes. Spine J 2003;3:100-5.

36. Trainor TJ, Trainor MA. Etiology of low back pain in athletes. Curr Sports Med Rep 2004;3:41-6.

37. Battie MC, Videman T, Kaprio J, et al. The Twin Spine Study: contributions to a changing view of disc degeneration. Spine J 2009;9:47-59.

38. Patel AA, Spiker WR, Daubs M, Brodke D, CannonAlbright LA. Evidence for an inherited predisposition to lumbar disc disease. J Bone Joint Surg Am 2011;93:225-9.

39. Stuber KJ, Bruno P, Sajko S, Hayden JA. Core stability exercises for low back pain in athletes: a systematic review of the literature. Clin J Sport Med 2014;24:448-56.

40. Manchikanti L, Singh V, Pampati V, et al. Evaluation of the relative contributions of various structures in chronic low back pain. Pain Physician 2001;4:308-16.

41. Watkins RG, Dillin WH. Lumbar spine injury in the athlete. Clin Sports Med 1990;9:419-48.

42. Vad VB, Cano WG, Basrai D, Lutz GE, Bhat AL. Role of radiofrequency denervation in lumbar zygapophyseal joint synovitis in baseball pitchers: a clinical experience. Pain Physician 2003;6:307-12.

43. Dreyfuss P, Halbrook B, Pauza K, Joshi A, McLarty J, Bogduk N. Efficacy and validity of radiofrequency neurotomy for chronic lumbar zygapophysial joint pain. Spine (Phila Pa 1976) 2000;25:1270-7.

44. Shifflett GD, Hellman MD, Louie PK, Mikhail C, Park KU, Phillips FM. Return to golf after lumbar fusion. Sports Health 2017;9:280-4.

45. Siepe CJ, Wiechert K, Khattab MF, Korge A, Mayer HM. Total lumbar disc replacement in athletes: clini- 
cal results, return to sport and athletic performance. Eur Spine J 2007;16:1001-13.

46. Tumialan LM, Ponton RP, Garvin A, Gluf WM. Arthroplasty in the military: a preliminary experience with ProDisc-C and ProDisc-L. Neurosurg Focus 2010;28:E18.

47. Micheli LJ, Wood R. Back pain in young athletes: significant differences from adults in causes and patterns. Arch Pediatr Adolesc Med 1995;149:15-8.

48. Amari R, Sakai T, Katoh S, et al. Fresh stress fractures of lumbar pedicles in an adolescent male ballet dancer: case report and literature review. Arch Orthop Trauma Surg 2009;129:397-401.

49. Papanicolaou N, Wilkinson RH, Emans JB, Treves $\mathrm{S}$, Micheli LJ. Bone scintigraphy and radiography in young athletes with low back pain. AJR Am J Roentgenol 1985;145:1039-44.

50. Rossi F, Dragoni S. Lumbar spondylolysis: occurrence in competitive athletes: updated achievements in a series of 390 cases. J Sports Med Phys Fitness 1990;30:450-2.

51. Soler T, Calderon C. The prevalence of spondylolysis in the Spanish elite athlete. Am J Sports Med 2000;28:57-62.

52. Kothari MK, Shah KC, Prabhoo T, Nene AM. Spondylolysis among fast bowlers: approach to management. J Postgrad Med Educ Res 2015;49:186-93.

53. Klein G, Mehlman CT, McCarty M. Nonoperative treatment of spondylolysis and grade I spondylolisthesis in children and young adults: a metaanalysis of observational studies. J Pediatr Orthop 2009;29:146-56.

54. El Rassi G, Takemitsu M, Woratanarat P, Shah SA. Lumbar spondylolysis in pediatric and adolescent soccer players. Am J Sports Med 2005;33:1688-93.

55. Miller SF, Congeni J, Swanson K. Long-term functional and anatomical follow-up of early detected spondylolysis in young athletes. Am J Sports Med 2004;32:928-33.

56. Kershen LM, Nacey NC, Patrie JT, Fox MG. Accuracy and efficacy of fluoroscopy-guided pars interarticularis injections on immediate and short-term pain relief. Skeletal Radiol 2016;45:1329-35.

57. Seitsalo S, Osterman K, Hyvarinen H, Tallroth K,
Schlenzka D, Poussa M. Progression of spondylolisthesis in children and adolescents: a long-term follow-up of 272 patients. Spine (Phila Pa 1976) 1991;16:417-21.

58. Gillis CC, Eichholz K, Thoman WJ, Fessler RG. A minimally invasive approach to defects of the pars interarticularis: restoring function in competitive athletes. Clin Neurol Neurosurg 2015;139:29-34.

59. Johnson JR, Kirwan EO. The long-term results of fusion in situ for severe spondylolisthesis. J Bone Joint Surg Br 1983;65:43-6.

60. Kip PC, Esses SI, Doherty BI, Alexander JW, Crawford MJ. Biomechanical testing of pars defect repairs. Spine (Phila Pa 1976) 1994;19:2692-7.

61. Snyder LA, Shufflebarger H, O'Brien MF, Thind H, Theodore N, Kakarla UK. Spondylolysis outcomes in adolescents after direct screw repair of the pars interarticularis. J Neurosurg Spine 2014;21:329-33.

62. Kolcun JPG, Chieng LO, Madhavan K, Wang MY. Minimally-invasive versus conventional repair of spondylolysis in athletes: a review of outcomes and return to play. Asian Spine J 2017;11:832-42.

63. Reitman CA, Esses SI. Direct repair of spondylolytic defects in young competitive athletes. Spine J 2002;2:142-4.

64. Hardcastle PH. Repair of spondylolysis in young fast bowlers. J Bone Joint Surg Br 1993;75:398-402.

65. Nozawa S, Shimizu K, Miyamoto K, Tanaka M. Repair of pars interarticularis defect by segmental wire fixation in young athletes with spondylolysis. Am J Sports Med 2003;31:359-64.

66. Helenius I, Lamberg T, Osterman K, et al. Scoliosis research society outcome instrument in evaluation of long-term surgical results in spondylolysis and lowgrade isthmic spondylolisthesis in young patients. Spine (Phila Pa 1976) 2005;30:336-41.

67. Lamberg T, Remes V, Helenius I, Schlenzka D, Seitsalo S, Poussa M. Uninstrumented in situ fusion for high-grade childhood and adolescent isthmic spondylolisthesis: long-term outcome. J Bone Joint Surg Am 2007;89:512-8.

68. Abla AA, Maroon JC, Lochhead R, Sonntag VK, Maroon A, Field M. Return to golf after spine surgery. J Neurosurg Spine 2011;14:23-30. 